\title{
Psychological factors affecting Marfan syndrome patients with or without cardiac surgery
}

\author{
Miklós Pólos ${ }^{1,2}$, Kálmán Benke ${ }^{1,2}$, Bence Ágg ${ }^{1,2,3}$, Roland Stengl $^{1}$, András Szabó ${ }^{4}$, Ádám Nagy $^{4}$, \\ Bernadett Ruskó $^{1}$, Julianna Hedberg ${ }^{1}$, Tamás Radovits ${ }^{1}$, Éva Susánszky ${ }^{5}$, Béla Merkely ${ }^{1}$, Andrea Székely ${ }^{4}$, \\ Zoltán Szabolcs ${ }^{1,2}$
}

${ }^{1}$ Heart and Vascular Center, Semmelweis University, Budapest, Hungary; ${ }^{2}$ Hungarian Marfan Foundation, Budapest, Hungary; ${ }^{3}$ Department of Pharmacology and Pharmacotherapy, Semmelweis University, Budapest, Hungary; ${ }^{4}$ Department of Anesthesiology and Intensive Therapy, Budapest, Hungary; ${ }^{5}$ Institute of Behavioural Sciences, Semmelweis University, Budapest, Hungary

Contributions: (I) Conception and design: M Pólos, K Benke, B Ágg, R Stengl; (II) Administrative support: M Pólos, K Benke, A Szabó, Á Nagy, B Ruskó; (III) Provision of study materials or patients: M Pólos, K Benke, J Hedberg, T Radovits, É Susánszky, B Merkely; (IV) Collection and assembly of data: M Pólos, K Benke, A Szabó, Z Szabolcs; (V) Data analysis and interpretation: M Pólos, K Benke; (VI) Manuscript writing: All authors; (VII) Final approval of manuscript: All authors.

Correspondence to: Miklós Pólos, MD. Heart and Vascular Center, Semmelweis University, H-1122 Varosmajor str. 68, Budapest, Hungary.

Email: miklospolos@gmail.com.

Background: Marfan syndrome (MFS) is a systemic connective tissue disorder belonging to a group of rare diseases. Several psychologically distressing factors can challenge life for MFS patients. The aim of the present study was, therefore, to assess the psychological and psychosocial aspects of MFS with the goal of identifying a means of improving disease management for patients.

Methods: A total of 66 adult patients with MFS were enrolled into the study prospectively and were divided into operated (OP) and non-operated (NOP) subgroups. Multiple questionnaire tests were used to determine the mental and physical state of our patients. Demographic and surgical data were collected. The results of the tests were also compared to the Hungarostudy (HS) population (representing the average Hungarian population) by using a propensity-matched control.

Results: OP group scores yielded more alcohol consumption $(\mathrm{P}<0.001)$, while NOP group showed more sleep disturbances. Scores on the MMSE, BECK, STAI and STAI-T tests showed no significant difference comparing the OP and NOP groups. MFS patients appear to have moderate pain-related disability and mild depressive symptoms and sleep disturbances $(\mathrm{P}<0.05)$ compared to the HS group. On 10-point scale, MFS patients were more satisfied with their lives $(\mathrm{P}<0.001)$ and considered themselves happier $(\mathrm{P}<0.001)$ than the HS population; however, they also spent more days on sick leave and in hospital over the past year. The HS group yielded a higher overall percentage of current smokers and pack-per-year consumption than the MFS patients overall $(\mathrm{P}=0.003$ and $\mathrm{P}<0.001$ respectively).

Conclusions: Marfan patients' psychosocial life differs in many ways (including sleep disturbances, healthier lifestyle, pain-related suffering) from the average Hungarian population. Therefore, as part of a multidisciplinary approach during treatment, modern management of MFS should include psychosocial exploration and psychological support in addition to traditional medical options.

Keywords: Marfan syndrome (MFS); anxiety; depression; pain

Submitted Mar 04, 2020. Accepted for publication Jul 01, 2020.

doi: $10.21037 / \mathrm{apm}-20-546$

View this article at: http://dx.doi.org/10.21037/apm-20-546 


\section{Introduction}

Marfan syndrome (MFS) is a systemic connective tissue disorder which belongs to a group of rare diseases with a prevalence of 1:5,000 (1). It is autosomal dominant, with similar frequency in both sexes and across countries and races (2). The characteristic traits of MFS are a result of a defect the fibrillin-1 protein from the encoding of FBN1 gene (3). Approximately $25 \%$ of MFS patients have a de novo FBN1 pathogenic variant, and $75 \%$ of the individuals diagnosed with the disease have an affected parent (3). Diagnosis is based on the revised Ghent nosology. The main clinical manifestations include the cardiovascular-, musculoskeletal- and ocular systems (4). Expression of symptoms and their severity vary among patients, but any of them can have a negative impact on life. The most dangerous consequence, with high mortality rate, is aortic dissection; therefore, preventative prophylactic surgery is crucial for high risk patients according to specific guidelines (5). Other characteristic traits such as ectopic lens, myopia, scoliosis, and pectus deformities are not life-threatening but can make life more difficult for the affected population.

Apart from physical complications, the above-mentioned manifestations of MFS can also lead to psychological and psychosocial problems. Existing studies on the disease have mostly focused on the physical aspects, therefore literature on the psychological and psychosocial burdens of the disease is sparse. Those studies that have been conducted in this area utilised small sample sizes, which limits their generalisability to a wider population. The importance of researching the mental and emotional health aspects of the disease must not be underestimated, however, as they greatly influence patients' everyday lives. Several psychologically distressing factors may present a significant challenge for MFS patients in everyday life (6). These include disrupted body image, debilitating physical limitations, uncertainty of the future, and the fear of transmitting the disease to their offspring (7). It has been found that the occurrence of aortic dissection alone has a huge impact on life quality, for example, as patients who underwent cardiac surgery due to this condition showed significantly higher trait anxiety levels than a healthy control group (6). Living with the risk of such a severe complication results in a significant burden on MFS patients and requires well-functioning coping mechanisms.A useful indicator of patient distress is an assessment of subjective life satisfaction levels. Velvin and colleagues found that an individual's satisfaction with life (SWL) score was significantly lower for MFS patients compared to the general Norwegian population. Furthermore, low SWL was primarily associated with aortic dissection, severe fatigue, and having regular contact with a psychologist for counselling (8). These findings indicate the necessity for further research in the area of MFS patients' mental health, and particularly suggest the need for psychologically distressing factors to be taken into consideration during patient management. The aim of the present study, therefore, was to assess the psychological and psychosocial aspects of MFS in order to provide additional insight into ways that might improve patient management in MFS.

We present the following article in accordance with the SURGE reporting checklist (available at http://dx.doi. org/10.21037/apm-20-546).

\section{Methods}

\section{Studied population}

The study was conducted in accordance with the Declaration of Helsinki (as revised in 2013) and was approved by the Regional Ethics Committee (SE-TUKEB 7/2016). All participants signed informed consent to participate. A total of 66 adult consecutive MFS patients were enrolled prospectively from the outpatient clinic (Outpatient Marfan Clinic) of The Heart and Vascular Center at Semmelweis University in Budapest between the dates of April 1, 2016 and November 30, 2018. All enrolled patients voluntarily completed the questionnaire forms completely. Demographics were collected, such as age, gender, living and educational status, and place of living. If patients had had surgery, the characteristics and type of operation were also recorded in the Hungarian Marfan Registry (9). The data was compared to the HS population, a free-access, nationally representative, face-to face household survey conducted in Hungary in the year 2013 $(n=2,000)$. Identical questions were compared to our study population by using a propensity matching method.

\section{Psychological questionnaires}

The Mini-Mental State Examination (MMSE) was used for mapping patients' function. The MMSE is a wellestablished cognitive impairment inventory used in daily clinical practice and is widely validated. It contains simple questions and problems in a number of areas: the time and place of the test, repeating lists of words, arithmetic (such 
as the serial sevens), language use and comprehension, and basic motor and visual-motor skills. The questionnaire is scored between 0 to 30 , and the cut-off values are 23, 18 and 9 , signifying mild, moderate, and severe cognitive impairment, respectively $(10,11)$.

For characterisation anxiety we used the State Trait Anxiety Inventory (STAI). The inventory represents two axes, the STAI-S and STAI-T. The first 20 questions refer to the transitional emotional status evoked by a stressful situation (STAI-S), like hospital admission or a surgical intervention. The STAI-T score reflects individual differences in chronic anxiety susceptibility. Answers are recorded on a four-level Likert scale, and each group is scored 20 to 80 . The Hungarian population has been carefully evaluated and has a well-documented STAI with acceptable validity and reliability (12) (Cronbach $\alpha=0.753$ ).

For detecting affective disorders, the Beck Depression Inventory (BDI) was selected for this research. The BDI is a 21-item questionnaire that has previously been used with cardiac patients (13). It is an established tool for depression screening, with each item evaluating a symptom of depression, such as bad mood, pessimistic outlook, feelings of guilt, and loss of appetite. Each item contains four sentences indicating degree of severity for that particular symptom. Answers are recorded on a four-level Likert scale, with the whole inventory receiving a score from 0 to 60 . The validity and reliability of the BDI are also well documented in the Hungarian population (14) (Cronbach $\alpha=0.880$ ).

The Somatic Symptom Severity Scale (Patient Health Questionnaire, PHQ15) identifies subjective level of intensity of 13 different physical symptoms, such as gastrointestinal dysfunctions, dizziness, chest pain, and dyspnoea. The final score is calculated by assigning scores of 0,1 , and 2 to response categories of "not at all", "bothered a little", and "bothered a lot", for each item. Also, 2 items from the mood module (fatigue and sleep) are scored 0 ("not at all"), 1 ("several days") or 2 ("more than half the days" or "nearly every day"). The question assessing pain caused by menstruation and dysmenorrhea was excluded, so the inventory was scored 0 to 28 for the purposes of this research. Scores of 5, 10, and 15 represent the cutpoints for low, medium, and high somatic symptom severity, respectively (15) (Cronbach $\alpha=0.864)$.

The Devins Illness Intrusiveness Rating Scale measures the effect of illness on various social issues. It encompasses 13 questions to represent illness-induced disruptions to lifestyle, activities, and interests that can compromise psychosocial well-being and contribute to emotional distress in chronic disease. A theoretical model is presented to specify the nature, determinants, and psychosocial consequences of illness intrusiveness and the causal pathways through which these factors are interrelated. Answers are provided on a seven-level Likert scale, and the inventory is scored from 13 to 91 (16) (Cronbach $\alpha=0.929$ ).

For the purpose of further analysing the structure of patients' social network, we used the Caldwell Social Support Dimension Scale. These questions ask for the intensity of different interpersonal relationships and support, such as the direct relatives, neighbours, workmates, and friends. We first summarised the points, and created distinct familiar (parents, husband, grandparents, children, and other relatives) and non-familiar (neighbours, schoolmates, workmates, other social or church community) support scores. Individuals' answers are recorded on a fourlevel Likert scale (17) (Cronbach $\alpha=0.670)$.

Finally, we used the short form of the Athens Insomnia Scale Inventory (AIS-5). It contains 5 questions and can register mild and severe insomnia. The cut-off score of the AIS-5 is $\geq 4$, which signifies potential insomnia (18-20) (Cronbach $\alpha=0.738$ ).

\section{Statistical methods}

The MFS cohort was divided into two groups according to treatment: operative group (OP, $n=24)$, and conservatively treated, non-surgical group (NOP, $n=42$ ). Descriptive data were generated for all variables (median, interquartile range, mean, SD). Sequential comparison between these groups was completed, such as socio-economic and demographic parameters, and the data generated from completed inventories. The Mann-Whitney $U$ test was selected for continuous variables, and chi square for discrete variables.

The first comparison was between the Hungarian representative group and the MFS patient group. The previously described statistical approach was utilised, with propensity score matching between the two groups. The propensity score was calculated by applying a multivariable logistic regression model, with MFS as the binominal dependent variable. Predictor variables were age, gender, and the residence location. The Hosmer-Lemeshow test was used to evaluate model reliability. [Hosmer-Lemeshow $\mathrm{C}=9.31 ; \mathrm{P}=0.316$ (df: 8)]. MFS patients were matched to individuals from the Hungarian representative group. A 1:1 nearest neighbour greedy matching without replacement 
was utilised to form pairs, using callipers with a width equal to 0.1 of the standard deviation of the logit of the propensity score. The outcomes and measured covariates were compared between the groups via paired $t$-test and Wilcoxon Signed Ranks test for continuous variables and McNemar test for ordinal or nominal variables.

Data management and analysis were performed using SPSS 20.0 (SPSS Inc., Chicago, Illinois). Reliability was calculated by using Cronbach's alpha. A $\mathrm{P}<0.05$ was considered to be statistically significant.

\section{Results}

Altogether 66 MFS patients registered in the Hungarian Marfan Registry (9) participated in this study. Of them 32 were males $(48 \%)$, and the median age of the examined population was 35 years.

The OP group included patients who underwent aortic root reconstruction carried out with either the Bentall, Tirone David or modified Yacoub technique (21). There were 24 patients in this category $(63 \%$ male, median age: 39.5). The NOP group consisted of 42 patients ( $40 \%$ male, median age: 29.5). Their characteristic traits can be found in Table 1.

The OP group was older $(\mathrm{P}<0.001)$, taller $(\mathrm{P}=0.005)$ and had a greater BMI $(\mathrm{P}=0.0045)$ than the NOP group. When asked to rate their subjective health condition, the OP group score was significantly lower $(\mathrm{P}=0.041)$. There was no significant difference in terms of pain and fatigue except for back pain, which showed a tendency to be higher for $\mathrm{OP}$ patients $(\mathrm{P}=0.074)$. Additionally, no differences were found between groups in scores on the Patient Health Questionnaire (PHQ15), which investigates the severity of certain symptoms over the last 4 weeks, and the Devins Illness Intrusiveness Rating Scale, which analyses how much the illness and/or its treatment interfere with different aspects of life. The two groups appeared to be satisfied with their lives at the same level according to their rating on a 10 -point scale. Alcohol consumption was more frequent $(\mathrm{P}<0.001)$ for $\mathrm{OP}$ patients. In terms of other lifestyle issues such as smoking and physical activity, the two populations did not differ. The NOP group had a higher score on the Athens Insomnia Scale $(\mathrm{P}=0.034)$, indicating sleep disturbances, in which the greatest difference was found in the final awakening category $(\mathrm{P}=0.032)$ (Table 2).

According to the result of the Caldwell Support Scale, NOP patients received greater help from their family $(\mathrm{P}=0.016)$ and reported that more people lived in the same household $(\mathrm{P}=0.015)$. The $\mathrm{OP}$ population appeared to be more educated $(\mathrm{P}=0.043)$. Their scores on the MMSE, BECK, STAI and STAI-T tests showed no notable difference.

The other part of the research used the HS population for comparison, which included 2,000 people (HS 2013). The median age of the HS population was 47 years, and the sex distribution was similar to the MFS patients (47.1\% male). Given the characteristic traits of MFS, they were taller $(\mathrm{P}<0.001)$ and had lower $\mathrm{BMI}(\mathrm{P}<0.001)$ than the HS group. On 10 -point scale, MFS patients were more satisfied with their lives $(\mathrm{P}<0.001)$ and considered themselves happier $(\mathrm{P}<0.001)$. However, they spent more days on sick leave $(\mathrm{P}<0.001)$ and in hospital $(\mathrm{P}<0.001)$ in the past year than the HS population. The same percentage of the examined populations reported actual body pain, but it had a greater impact on everyday life for the HS group $(\mathrm{P}<0.001)$. The PHQ15 score was higher for MFS patients $(\mathrm{P}=0.002)$, however, meaning that certain symptoms were more severe for this group during the past 4 weeks. Given their results on the Devin's Illness Intrusiveness Rating Scale, their illness and/or its treatment interfered with their life at the same level (Table S1).

Lifestyles also showed many differences between MFS and HS groups. In the HS group the percentage of current smokers and the pack-year unit were higher $(\mathrm{P}=0.003$ and $\mathrm{P}<0.001$ respectively). As expected, according to their lifestyle restrictions, MFS patients did sport and other physical activities less frequently $(\mathrm{P}<0.001)$. Alcohol consumption was similar among the two populations. The MFS group reported a higher occurrence of sleep disturbances based on their Athens Insomnia Scale $(\mathrm{P}<0.001)$. The proportion of unmarried people with no partner was greater in the MFS group $(\mathrm{P}<0.001)$. They reported better financial subjective assessment $(\mathrm{P}<0.001)$ and among them the critical low income was less frequent $(\mathrm{P}=0.009)$. They also reached higher education levels $(\mathrm{P}=0.009)$ than the HS group.

We also made comparisons between paired subgroups of the HS and MFS categories (Table 3) with 59 patients in each one. Both subgroups had 30 males. No difference could be observed in terms of subjective happiness, and life satisfaction only showed a tendency being higher in the MFS group $(\mathrm{P}=0.074)$. A further difference was the number of people living in the same household being larger for the HS group ( $\mathrm{P}=0.006)$. All the other aspects appeared to have similar results to the above described non-paired HS-MFS comparison. 
Table 1 Baseline charactheristics of Marfan patients according to the revised Ghent nosology

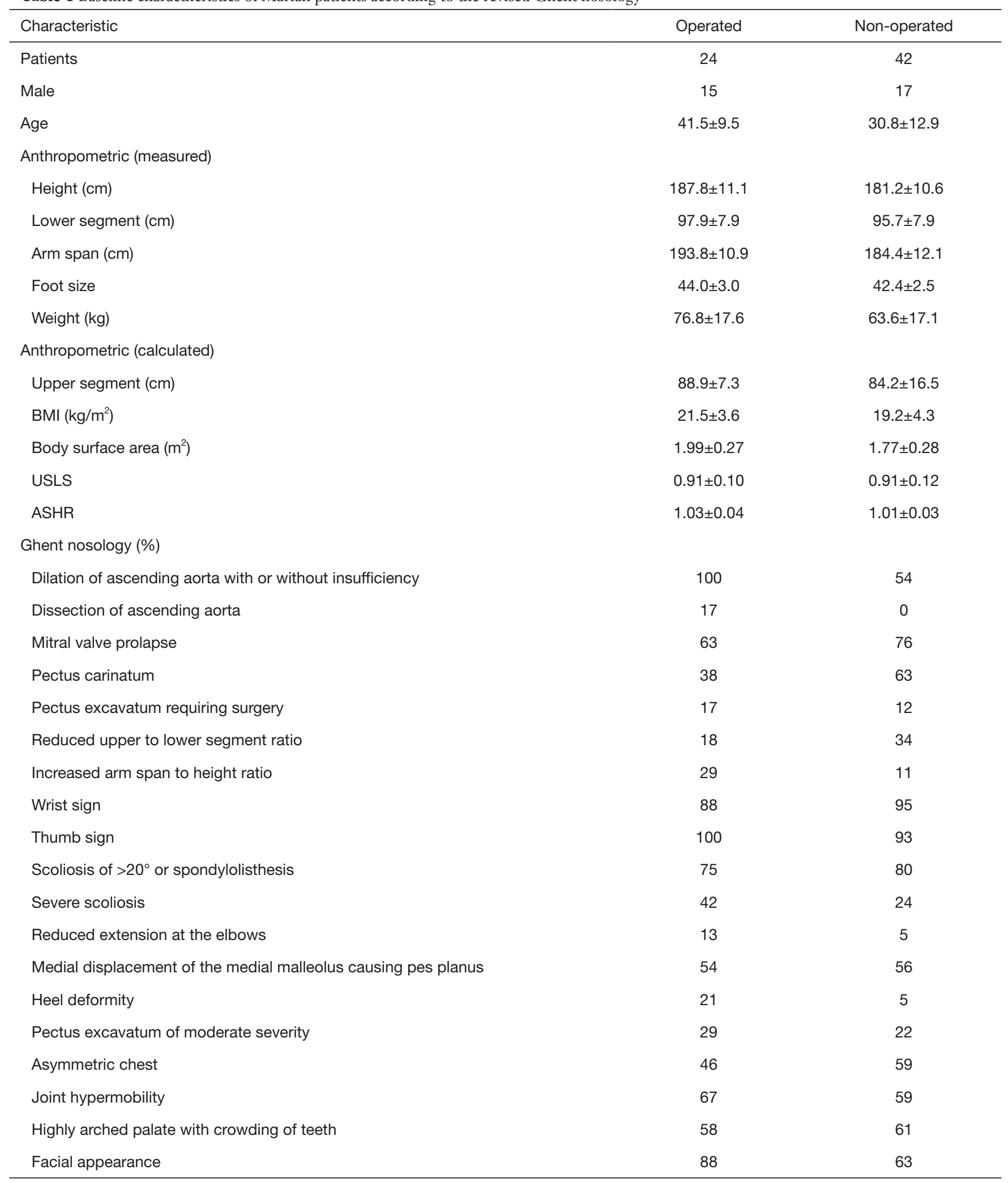

Table 1 (continued) 
Table 1 (continued)

\begin{tabular}{lcc}
\hline Characteristic & Operated & Non-operated \\
\hline Ectopia lentis & 33 & 22 \\
Myopia over 3 diopters & 63 & 39 \\
Spontaneous pneumothorax & 13 & 7 \\
Striae atrophicae (stretch marks) & 58 & 63 \\
Systemic score & $7.96 \pm 1.65$ & $8.1 \pm 1.5$ \\
\hline
\end{tabular}

USLS, upper segment/lower segment ratio; ASHR, arm span/height ratio.

Table 2 Results of the patient questionnaires in the examined Marfan population

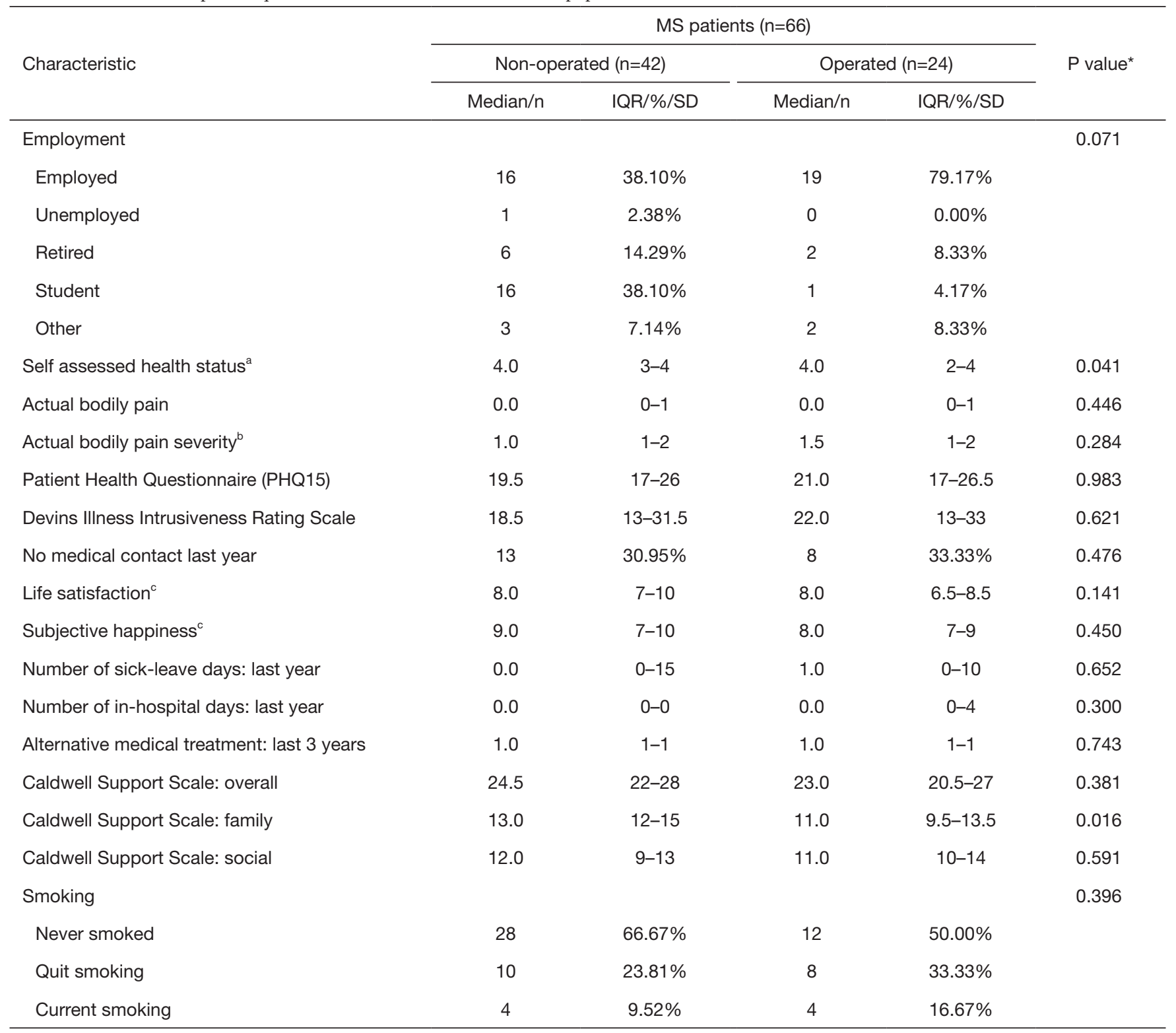

Table 2 (continued) 
Table 2 (continued)

\begin{tabular}{|c|c|c|c|c|c|}
\hline \multirow{2}{*}{ Characteristic } & \multicolumn{4}{|c|}{ MS patients $(n=66)$} & \multirow{2}{*}{$P$ value } \\
\hline & Median/n & $\mathrm{IQR} / \% / \mathrm{SD}$ & Median/n & $\mathrm{IQR} / \% / \mathrm{SD}$ & \\
\hline Pack-year unit & 0.0 & $0-0$ & 0.0 & $0-0$ & 0.935 \\
\hline Physical activity (number/week) & 2.0 & $1-3$ & 2.0 & $1-3$ & 0.379 \\
\hline Drinking alcoholic beverages ${ }^{d}$ & 1.8 & \pm 1.0 & 2.8 & \pm 1.1 & $<0.001$ \\
\hline Problem with sleep induction & 1.0 & $1-1$ & 1.0 & $1-1$ & 0.168 \\
\hline Final awakening & 2.0 & $1-2$ & 1.0 & $1-2$ & 0.032 \\
\hline Functional capacity during the day & 1.0 & $1-1$ & 1.0 & $1-1$ & 0.401 \\
\hline Athens Insomnia Scale (AIS5) & 7.0 & $6-8$ & 6.0 & $5-7$ & 0.034 \\
\hline Religion $^{\mathrm{e}}$ & 2.0 & $1-3$ & 2.0 & $1-3$ & 0.739 \\
\hline Importance of religion ${ }^{f}$ & 1.0 & $1-2$ & 2.0 & $1-2$ & 0.343 \\
\hline Education $^{9}$ & 4.0 & $2.5-5$ & 5.0 & $3.5-6$ & 0.043 \\
\hline Marital status & & & & & 0.165 \\
\hline Unmarried, no partner & 18 & $42.86 \%$ & 8 & $33.33 \%$ & \\
\hline Unmarried, living with a partner & 9 & $21.43 \%$ & 3 & $12.50 \%$ & \\
\hline Married & 10 & $23.81 \%$ & 9 & $37.50 \%$ & \\
\hline Beck & 4.5 & $2-8$ & 4.0 & $1-11$ & 0.777 \\
\hline STAI & 33.5 & $30-41$ & 37.0 & $29-40$ & 0.943 \\
\hline STAI-T & 37.0 & $31-44$ & 39.0 & $31-45$ & 0.759 \\
\hline
\end{tabular}

*, Mann Whitney U test: continouos variables, chi square test: ordinal/nominal variables. ${ }^{\text {, }}$, 1: very poor; 5: excellent. ${ }^{\mathrm{b}}$, 1: no/weak influence; 3: strong influence. ${ }^{c}, 1$ : absolutely not; 10: absolutely. ${ }^{d}, 1$ : never; 5: more fr. ${ }^{e}, 1$ : not religious; 5: very religious. ${ }^{f}, 1$ : not important; 4:very important. ${ }^{g}, 1$ : less, than primary school; 6: university. ${ }^{h}, 1$ : very poor; 10, excellent. PHQ15, Patient Health Questionnaire; AIS5, Athens Insomnia Scale; MMSE, Mini-Mental State Examination; STAI, State Trait Anxiety Inventory.

\section{Discussion}

MFS is a rare connective tissue disorder, affects 1 in every 5,000 individuals, across race and culture. It is autosomal dominant in heritability and can be caused by many different possible mutations of the FBN1 gene, which can include single nucleotide variations, small insertions or deletions, or copy number variations with consequent alterations in transforming growth factor- $\beta$ (TGF- $\beta$ ) signalling $(22,23)$. MFS has the potential to lead to acute aortic dissection, a life-threatening complication, of which the risk and occurrence is currently difficult to 
Table 3 Results of the propensity score matched HS population compared with the examined Marfan patients

\begin{tabular}{|c|c|c|c|c|c|c|}
\hline \multirow[t]{2}{*}{ Characteristic } & \multicolumn{2}{|c|}{$\begin{array}{l}\text { Paired subgroup of } \\
\text { Hungarostudy }(n=59)\end{array}$} & \multicolumn{2}{|c|}{$\begin{array}{l}\text { Paired subgroup } \\
\text { with MS }(n=59)\end{array}$} & \multirow[t]{2}{*}{$P$ value* } & \multirow[t]{2}{*}{$P$ value ${ }^{\star \star}$} \\
\hline & Median/n & IQR/\% & Median/n & IQR/\% & & \\
\hline Height (cm) & 170.0 & $165-176$ & 183.5 & $176-197.5$ & $<0.001$ & $<0.001$ \\
\hline Employed & 28 & $47.46 \%$ & 35 & $59.32 \%$ & & \\
\hline Unemployed & 13 & $22.03 \%$ & 1 & $1.69 \%$ & & \\
\hline Retired & 3 & $5.08 \%$ & 8 & $13.56 \%$ & & \\
\hline Actual bodily pain & 15 & $25.40 \%$ & 19 & $32.40 \%$ & 0.541 & 0.541 \\
\hline Patient Health Questionnaire (PHQ15) & 17.0 & $14-22.25$ & 22.0 & $19-27$ & 0.002 & 0.002 \\
\hline Life satisfaction $^{c}$ & 7.0 & $5-8$ & 9.0 & $7.25-9$ & 0.074 & 0.088 \\
\hline Subjective happiness ${ }^{c}$ & 8.0 & $5-9$ & 9.0 & $7-10$ & 0.127 & 0.149 \\
\hline Sick-leave days: last year & 7.0 & $11.9 \%$ & 24.0 & $40.7 \%$ & - & $<0.001$ \\
\hline Hospitalization: last year & 4.0 & $6.8 \%$ & 15.0 & $25.4 \%$ & - & 0.006 \\
\hline Alternative medical treatment: last 3 years & 2 & $3.40 \%$ & 12 & $20.30 \%$ & 0.013 & 0.013 \\
\hline Athens Insomnia Scale (AIS5) & 2.0 & $1-3$ & 2.0 & $1-3$ & 0.237 & 0.271 \\
\hline Education $^{g}$ & 4.0 & $3-6$ & 5.0 & $4-6$ & 0.057 & 0.040 \\
\hline Marital status & & & & & 0.003 & 0.006 \\
\hline Unmarried, no partner & 13 & $22.03 \%$ & 22 & $37.29 \%$ & & \\
\hline Unmarried, living with a partner & 11 & $18.64 \%$ & 12 & $20.34 \%$ & & \\
\hline Married & 25 & $42.37 \%$ & 19 & $32.20 \%$ & & \\
\hline Divorced & 10 & $16.95 \%$ & 6 & $10.17 \%$ & & \\
\hline Number of person living in a same household & 3.0 & $2-4$ & 2.0 & $2-3$ & 0.006 & 0.009 \\
\hline Financial subjective assessment ${ }^{\mathrm{h}}$ & 4.0 & $3-6.75$ & 6.0 & $5-7$ & $<0.001$ & $<0.001$ \\
\hline Critical low income & 19 & $32.20 \%$ & 4 & $6.80 \%$ & $<0.001$ & $<0.001$ \\
\hline
\end{tabular}

*, paired t-test. ${ }^{* *}$, Wilcoxon Signed Ranks test: continouos variables; McNemar test: ordinal/nominal variables. ${ }^{a}, 1:$ very poor; 5: excellent. b, 1: no/weak influence; 3: strong influence. ${ }^{c}, 1$ : absolutely not; 10: absolutely. ${ }^{d}, 1$ : never; 5: more fr. ${ }^{e}, 1$ : not religious; 5: very religious. f, 1: not important; 4:very important. ${ }^{9}, 1$ : less, than primary school; 6 : university. ${ }^{\text {, }}, 1$ : very poor; 10, excellent. PHQ15, Patient Health Questionnaire; AIS5, Athens Insomnia Scale. 
predict by simple measures (24). As such, the research at hand made the assumption that Marfan patients are also affected psychosocially in their everyday life due to disease awareness. We performed a cross-sectional, questionnairebased study to examine a representative cohort of Marfan patients. Even though this cohort only consists of 66 patients, this study population makes up quarter of the systematically followed Marfan patients in Hungary. After analysis, we compared the Marfan cohort data with the average Hungarian population.

While there is an overall lack of information on psychosocial disturbances in MFS, there are a few publications in the medical literature relating to our focus. Velvin and his colleagues investigated life satisfaction levels of 73 MFS patients and compared it to the general Norwegian population. They found scores on "Satisfaction With Life" questionnaire to be significantly lower for the MFS population (8). In our study, MFS patients had a significantly higher score on the same questionnaire than the HS population. The reason for that difference between the two study might be by the disparity between the two control groups (e.g., age, general health condition). As the HS population had a median age of 47 years, they are more likely to suffer from one or more diseases that lead to lower life satisfaction. It can be reinforced by the result of the comparison of the paired subgroups. However, while the difference is not significant, it shows a tendency towards MFS patients being more satisfied with their lives. Their satisfaction could also indicate that they are able to cope better with difficulties that come with the disease.

Another commonly reported MFS symptom relevant in the study of psychosocial disturbance is pain. One study performed by Speed et al. involving 245 participants investigated the frequency and effects of pain among MFS patients. According to their results $89 \%$ reported having pain, with $28 \%$ reporting pain as a presenting symptom of their MFS experience. Overall, those questioned appeared to have a moderate level of pain-related disability and a mild level of depressive symptoms, sleep disturbances and pain catastrophizing (25). These results remain consistent in our findings: higher PHQ15 score reflects the experience of more severe symptoms, including certain types of pain, and especially of back pain. More frequent back pain in this sample is possibly due to severe scoliosis and chest deformities, which are typical Marfan features. The finding that pain has a greater impact on everyday life in the HS group may indicate that MFS patients have learned to adapt to more severe pain since their childhood than the control sample.

More frequent alcohol consumption in the OP group was another interesting result. On one hand, this finding could indicate higher stress levels, especially for individuals with previous aortic dissection (6), and on the other hand it could be attributed to the belief that their disease has been taken care of and managed with the surgery, so the need to be conscious of their own health state is reduced. The fact that these same subjects rate their subjective health condition as lower does not contradict this possibility, because the need for an operation has already been indicative of a serious health problem, even if it is currently under control.

The NOP group's higher score on the Athens Insomnia Scale can support the latter idea. They live daily with the reality that they may develop a life-threatening aortic dissection. This awareness can serve to increase distress levels, manifesting as sleep disturbances. The OP group may feel safer due to previous surgical managementespecially those who received prophylactic surgery. Sleep disturbances such as those described here are often reported in MFS literature. Speed and colleagues found sleeping difficulties present among MFS patients, and that these were significantly worse when pain had spread from its initial location (25). Sleep apnea is also found to be more frequent for MFS patients in several studies. Rybczynski and colleagues examined 68 adult patients with MFS, and reported that $33 \%$ of them exhibited sleep apnea compared to $12 \%$ of the general population of similar age (26). It is an important finding, as there may be a correlation between obstructive sleep apnea (OSA) and aortic diameter (27). OSA could also be associated with aortic dissection (28). According to these findings, sleep difficulties should be further evaluated in MFS patients.

MFS patients seem to be following their lifestyle advices and leading a healthier life in terms of smoking, which might mean a good level of compliance.

The current findings on marital status are consistent with international literature. MFS patients often have low self-esteem, lack of self-confidence, and a large percentage of them are introverted (7). One study found that more than $90 \%$ of MFS patients surveyed reported that sexual encounters were negatively affected by their disease (29). This can make it difficult for them to build relationships.

One study involving 30 school-age children with MFS found that $51 \%$ had one or more neuropsychological deficits, such as a learning disability (30). The MFS patients in the current study reached a higher educational level than the control HS group, however. This may have 
a complex explanation: one possibility is that physical restrictions which prevent engaging in physical work leave MFS patients with intellectual work as their main income and self-esteem generating option. This often requires higher education. This can also explain findings on the better subjective assessment of financial situation and lower incidence of critically low income among them.

\section{Conclusions}

In summary, the current study found that Marfan patients' psychosocial life differs from the average Hungarian population in many ways. Sometimes a need appears in our Marfan patients for help to cope with the psychological consequences of their genetic disorder. Therefore, as part of a multidisciplinary approach, management of MFS should also strive to include psychosocial exploration and support. Our study has limitations. The sample size of Marfan patients participated in this evaluation could be increased. On the other hand, not only clinical diagnosis but genetic screening of every Marfan patients could be further strengthening our conclusion.

\section{Acknowledgments}

The authors would like to thank all the patients who took part in the examinations and sample collection. We also thank all the members of the Hungarian Marfan Foundation for enabling us to carry out this research.

Funding: This study was supported by the National Research, Development, and Innovation Office of Hungary (NKFIH; NVKP-16-1-2016-0017, "National Heart Program"), by the Higher Education Institutional Excellence Program of the Ministry of Human Capacities in Hungary, within the framework of the Therapeutic Development thematic program of Semmelweis University.

\section{Footnote}

Reporting Checklist: The authors have completed the SURGE reporting checklist. Available at http://dx.doi. org/10.21037/apm-20-546

Data Sharing Statement: Available at http://dx.doi. org/10.21037/apm-20-546

Conflicts of Interest: All authors have completed the ICMJE uniform disclosure form (available at http://dx.doi. org/10.21037/apm-20-546). BÁ, KB, MP, BM, ZS and TR report grants from National Research, Development, and Innovation Office of Hungary NKFIH; NVKP-16-1-20160017, "National Heart Program", during the conduct of the study. The authors have no other conflicts of interest to declare.

Ethical Statement: The authors are accountable for all aspects of the work in ensuring that questions related to the accuracy or integrity of any part of the work are appropriately investigated and resolved. The study was conducted in accordance with the Declaration of Helsinki (as revised in 2013) and was approved by the Regional Ethics Committee (SE-TUKEB 7/2016). All participants signed informed consent to participate.

Open Access Statement: This is an Open Access article distributed in accordance with the Creative Commons Attribution-NonCommercial-NoDerivs 4.0 International License (CC BY-NC-ND 4.0), which permits the noncommercial replication and distribution of the article with the strict proviso that no changes or edits are made and the original work is properly cited (including links to both the formal publication through the relevant DOI and the license). See: https://creativecommons.org/licenses/by-nc-nd/4.0/.

\section{References}

1. Milewicz DM, Dietz HC, Miller DC. Treatment of aortic disease in patients with Marfan syndrome. Circulation 2005;111:e150-7.

2. von Kodolitsch Y, De Backer J, Schüler H, et al. Perspectives on the revised Ghent criteria for the diagnosis of Marfan syndrome. Appl Clin Genet 2015;8:137-55.

3. Dietz HC, Cutting GR, Pyeritz RE, et al. Marfan syndrome caused by a recurrent de novo missense mutation in the fibrillin gene. Nature 1991;352:337-9.

4. Loeys BL, Dietz HC, Braverman AC, et al. The revised Ghent nosology for the Marfan syndrome. J Med Genet 2010;47:476-85.

5. Baumgartner H, Falk V, Bax JJ, et al. 2017 ESC/EACTS Guidelines for the management of valvular heart disease. Eur Heart J 2017;38:2739-91.

6. Benke K, Agg B, Polos M, et al. The effects of acute and elective cardiac surgery on the anxiety traits of patients with Marfan syndrome. BMC Psychiatry 2017;17:253 .

7. Van Tongerloo A, De Paepe A. Psychosocial adaptation in adolescents and young adults with Marfan syndrome: an 
exploratory study. J Med Genet 1998;35:405-9.

8. Velvin G, Bathen T, Rand-Hendriksen S, et al. Satisfaction with life in adults with Marfan syndrome (MFS): associations with health-related consequences of MFS, pain, fatigue, and demographic factors. Qual Life Res 2016;25:1779-90.

9. Agota A, Agg B, Benke K, et al. The establishment of the Marfan syndrome biobank in Hungary. Orv Hetil 2012;153:296-302.

10. Folstein MF, Folstein SE, McHugh PR. "Mini-mental state". A practical method for grading the cognitive state of patients for the clinician. J Psychiatr Res 1975;12:189-98.

11. Crum RM, Anthony JC, Bassett SS, et al. Populationbased norms for the Mini-Mental State Examination by age and educational level. JAMA 1993;269:2386-91.

12. Székely A, Balog P, Benkö E, et al. Anxiety predicts mortality and morbidity after coronary artery and valve surgery--a 4-year follow-up study. Psychosom Med 2007;69:625-31.

13. Beck AT, Ward CH, Mendelson M, et al. An inventory for measuring depression. Arch Gen Psychiatry 1961;4:561-71.

14. Kopp MS, Falger PR, Appels A, et al. Depressive symptomatology and vital exhaustion are differentially related to behavioral risk factors for coronary artery disease. Psychosom Med 1998;60:752-8.

15. Spitzer RL, Kroenke K, Williams JB. Validation and utility of a self-report version of PRIME-MD: the PHQ primary care study. Primary Care Evaluation of Mental Disorders. Patient Health Questionnaire. JAMA 1999;282:1737-44.

16. Devins GM. Illness intrusiveness and the psychosocial impact of lifestyle disruptions in chronic life-threatening disease. Adv Ren Replace Ther 1994;1:251-63.

17. Caldwell RA, Pearson JL, Chin RJ. Stress-Moderating Effects: Social Support in the Context of Gender and Locus of Control. Personality and Social Psychology Bulletin, 1987:5-17.

18. Enomoto K, Adachi T, Yamada K, et al. Reliability and

Cite this article as: Pólos M, Benke K, Ágg B, Stengl R, Szabó A, Nagy Á, Ruskó B, Hedberg J, Radovits T, Susánszky É, Merkely B, Székely A, Szabolcs Z. Psychological factors affecting Marfan syndrome patients with or without cardiac surgery. Ann Palliat Med 2020;9(5):3007-3017. doi: 10.21037/apm20-546 validity of the Athens Insomnia Scale in chronic pain patients. J Pain Res 2018;11:793-801.

19. Soldatos CR, Dikeos DG, Paparrigopoulos TJ. The diagnostic validity of the Athens Insomnia Scale. J Psychosom Res 2003;55:263-7.

20. Soldatos CR, Dikeos DG, Paparrigopoulos TJ. Athens Insomnia Scale: validation of an instrument based on ICD10 criteria. J Psychosom Res 2000;48:555-60.

21. Benke K, Agg B, Szabo L, et al. Bentall procedure: quarter century of clinical experiences of a single surgeon. J Cardiothorac Surg 2016;11:19.

22. Benke K, Agg B, Meienberg J, et al. Hungarian Marfan family with large FBN1 deletion calls attention to copy number variation detection in the current NGS era. J Thorac Dis 2018;10:2456-60.

23. Benke K, Agg B, Szilveszter B, et al. The role of transforming growth factor-beta in Marfan syndrome. Cardiol J 2013;20:227-34.

24. Agg B, Benke K, Szilveszter B, et al. Possible extracardiac predictors of aortic dissection in Marfan syndrome. BMC Cardiovasc Disord 2014;14:47.

25. Speed TJ, Mathur VA, Hand M, et al. Characterization of pain, disability, and psychological burden in Marfan syndrome. Am J Med Genet A 2017;173:315-23.

26. Rybczynski M, Koschyk D, Karmeier A, et al. Frequency of sleep apnea in adults with the Marfan syndrome. Am J Cardiol 2010;105:1836-41.

27. Kohler M, Blair E, Risby P, et al. The prevalence of obstructive sleep apnoea and its association with aortic dilatation in Marfan's syndrome. Thorax 2009;64:162-6.

28. Sampol G, Romero O, Salas A, et al. Obstructive sleep apnea and thoracic aorta dissection. Am J Respir Crit Care Med 2003;168:1528-31.

29. De Bie S, De Paepe A, Delvaux I, et al. Marfan syndrome in Europe. Community Genet 2004;7:216-25.

30. Hofman KJ, Bernhardt BA, Pyeritz RE. Marfan syndrome: neuropsychological aspects. Am J Med Genet 1988;31:331-8. 
Table S1 Results of the HS population compared with the examined Marfan patients

\begin{tabular}{|c|c|c|c|c|c|}
\hline \multirow{2}{*}{ Characteristic } & \multicolumn{2}{|c|}{ Hungarostudy population $(n=2,000)$} & \multicolumn{2}{|c|}{ Marfan syndrome patients $(n=66)$} & \multirow{2}{*}{$P$ value* } \\
\hline & Median/n/mode & IQR/\% & Median/n/mode & IQR/\% & \\
\hline Age (years) & 47 & $33-61$ & 35 & $23-43$ & $<0.001$ \\
\hline Gender (male) & 942 & 47.10 & 32 & 48.50 & 0.461 \\
\hline Height (cm) & 170.0 & $164-176$ & 182.0 & $176-195$ & $<0.001$ \\
\hline Weight (kg) & 75.0 & $64-85$ & 65.5 & $57.5-82.5$ & 0.005 \\
\hline BMI & 25.39 & $22.76-29.00$ & 20.36 & $17.13-24.18$ & $<0.001$ \\
\hline Employment & & & & & 0.382 \\
\hline Employed & 973 & $49.77 \%$ & 35 & $55.6 \%$ & \\
\hline Unemployed & 164 & $8.4 \%$ & 1 & $1.5 \%$ & \\
\hline Retired & 602 & $30.79 \%$ & 8 & $10.6 \%$ & \\
\hline Student & 130 & $6.5 \%$ & 17 & $25.8 \%$ & \\
\hline Other & 86 & $4.4 \%$ & 2 & $3.0 \%$ & \\
\hline Self assessed health status ${ }^{a}$ & 4.0 & $3-4$ & 4.0 & $3-4$ & 0.551 \\
\hline Actual bodily pain & 726 & $36.40 \%$ & 20 & $30.30 \%$ & 0.190 \\
\hline Actual bodily pain severity ${ }^{\mathrm{b}}$ & 2.0 & $2-2$ & 1.0 & $1-2$ & $<0.001$ \\
\hline Patient Health Questionnaire (PHQ15) & 18.0 & $14-24$ & 20.0 & $17-26$ & 0.002 \\
\hline No medical contact: last year & 1095 & $54.75 \%$ & 21 & $31.82 \%$ & 0.061 \\
\hline Devins IIIness Intrusiveness Rating Scale & 26.0 & 23-38 & 19.0 & $13-32$ & 0.201 \\
\hline Life satisfaction $^{\circ}$ & 7.0 & $5-8$ & 8.0 & $7-9$ & $<0.001$ \\
\hline Subjective happiness $^{c}$ & 7.0 & $5-8$ & 8.5 & $7-10$ & $<0.001$ \\
\hline Sick-leave days: last year & 266 & $17.9 \%$ & 26 & $46.4 \%$ & $<0.001$ \\
\hline Hospitalization: last year & 213 & $11.3 \%$ & 17 & $27.9 \%$ & $<0.001$ \\
\hline Alternative medical treatment: last 3 years & 0.0 & $0-0$ & 1.0 & $1-1$ & $<0.001$ \\
\hline Caldwell Support Scale: overall & 23.0 & $19-27$ & 24.0 & $21-28$ & 0.136 \\
\hline Caldwell Support Scale: family & 12.0 & $10-15$ & 12.0 & $11-14$ & 0.586 \\
\hline Caldwell Support Scale: social & 11.0 & $9-14$ & 12.0 & $10-14$ & 0.675 \\
\hline Smoking & & & & & 0.003 \\
\hline Never smoked & 1034 & $51.80 \%$ & 40 & $60.6 \%$ & \\
\hline Quit smoking & 347 & $17.40 \%$ & 18 & $27.3 \%$ & \\
\hline Current smoking & 617 & $30.90 \%$ & 8 & $12.1 \%$ & \\
\hline Pack-year unit & 12.75 & $5.5-23.75$ & 6.0 & $0.5-19.0$ & 0.042 \\
\hline Physical activity (number/week) & 5.0 & $3-7$ & 2.0 & $1-4$ & $<0.001$ \\
\hline Other exercise (number/week) & 3.0 & $2-4$ & 1.0 & $0-3$ & $<0.001$ \\
\hline Drinking alcoholic beverages ${ }^{d}$ & 2.0 & $1-3$ & 2.0 & $1-3$ & 0.646 \\
\hline Athens Insomnia Scale (AIS5) & 2.0 & $1-4$ & 7.0 & $6-8$ & $<0.001$ \\
\hline Religion $^{e}$ & 2.0 & $1-3$ & 2.0 & $1-3$ & 0.280 \\
\hline Importance of religion ${ }^{f}$ & 2.0 & $1-2$ & 1.0 & $1-2$ & 0.497 \\
\hline Education $^{9}$ & 3.0 & & 4.0 & & 0.009 \\
\hline Marital status & & & & & $<0.001$ \\
\hline Unmarried, no partner & 413 & $20.73 \%$ & 26 & $41.27 \%$ & \\
\hline Unmarried, living with a partner & 185 & $9.29 \%$ & 12 & $19.05 \%$ & \\
\hline Married & 891 & $44.73 \%$ & 19 & $30.16 \%$ & \\
\hline Divorced & 260 & $13.05 \%$ & 6 & $9.52 \%$ & \\
\hline Widowed & 233 & $11.70 \%$ & 0 & $0.00 \%$ & \\
\hline Number of person living in a same household & 2.0 & $2-4$ & 2.5 & $2-4$ & 0.894 \\
\hline Financial subjective assessment ${ }^{h}$ & 5.0 & $3-6$ & 5.5 & $5-7$ & $<0.001$ \\
\hline Critical low income & 367 & $19.20 \%$ & 4 & $6.90 \%$ & 0.009 \\
\hline
\end{tabular}

*, Mann Whitney U test: continouos variables, chi square test: ordinal/nominal variables. ${ }^{a}, 1$ : very poor; $5:$ excellent. ${ }^{\mathrm{b}}, 1:$ no/weak influence; 3: strong influence. ${ }^{c}, 1$ : absolutely not; 10: absolutely. ${ }^{d}, 1$ : never; 5 : more fr. ${ }^{e}, 1$ : not religious; 5: very religious. ${ }^{\dagger}, 1$ : not important; 4:very important. ${ }^{g}, 1$ : less, than primary school; 6: university. ${ }^{h}, 1$ : very poor; 10, excellent. PHQ15, Patient Health Questionnaire; AIS5, Athens Insomnia Scale. 